\title{
Impact of Rural-Urban Labour Migration on Education of Children: A Case Study of Left Behind and Accompanied Migrant Children in India
}

\author{
Dr Archana K Roy ${ }^{+* *}$ Pappu Singh* and Prof. UN Roy ${ }^{\top}$
}

\section{Abstract}

In developing countries, seasonal labour migration from rural to urban or from backward to developed region is a household livelihood strategy to cope with poverty. In this process, the children of those migrants are the worst affected whether they accompany their parents or are left behind in the villages. The present paper explores the impact of temporary labour migration of parent(s) on school attendance of the children between 6-14 years and their dropping out from the school through an analysis of the cases from both the ends of migration stream in India. Data was collected from thirteen construction sites of Varanasi Uttar Pradesh and nine villages of Bihar by applying both qualitative and quantitative techniques. It is evident from the study that the migrants through remittances improve school accessibility for the left behind children and bridge gender gap in primary school education. However, among the accompanying migrant children of construction workers, many remain out of school and many are forced to drop out and some of them become vulnerable to work as child labour due to seasonal mobility of their parents. Thus, mainstreaming these children in development process is a big challenge in attaining the goal of universal primary education and inclusive growth in the country like India.

Key words: School dropout, seasonal labour migration, left behind children, caste system, poverty, Eastern Uttar Pradesh and Bihar, India

\footnotetext{
${ }^{\dagger}$ Associate Professor, Department of Migration and Urban Studies, International Institute for Population Sciences (IIPS), Mumbai 400088, India, Email: royarchna@yahoo.com

*Assistant Teacher-Geography, Mangal Seminary Inter College, Motihari, East Chanparan-845401, Bihar, India, Email: pappusinghbhu@gmail.com

'̇ Professor, Department of Rural Development, National Institute of Technical Teachers Training and Research (NITTTR), Chandigarh, India-160019, Email: unroy2000@yahoo.com

${ }^{* *}$ Corresponding Author

(C)2015 Roy et al. This is an Open Access article distributed under the terms of the Creative Commons Attribution License (http://creativecommons.org/licenses/by/2.0), which permits unrestricted use, distribution, and reproduction in any medium, provided the original work is properly cited.
} 


\section{Introduction}

In developing countries, a large number of children are affected by temporary labour migration. Living in a family with at least one parent away for long periods is part of normal childhood experience for many children in these countries (Nobles, 2013). Children who are left behind or who migrate with their parents face several challenges in terms of education and health care. They suffer through various psycho-social problems and are exposed to exploitation (Bakker et al., 2009). Education is one of the critical issues as the window of opportunities for these children is limited (Smita, 2008). Therefore, the inclusion of migrant's children may have implications in achieving the target of universal primary education and reducing child labour. It is an important issue of migration studies but very few researchers have addressed this problem (Whitehead \& Hashim 2005; UNICEF n.d.), particularly in the context of internal migration.

It is difficult to make a precise estimate of the number of children who are left behind or who accompany their migrant parents around the globe due to their mobile nature. However, empirical evidences show that number of children affected by migration is very high. For example, $18-40 \%$ of children in Bangladesh, $50-60 \%$ in Tanzania and $80 \%$ in Mali were reported living in migrant households in rural areas (c.f. Whitehead \& Hashim, 2005). Roughly one million in Indonesia and half-a-million children in Thailand have been left behind by parents working overseas (Bryant, 2005). In India too, it is empirically evident (Singh \& Yadava 1981; Sajjad 1998; Pattanaik 2009; Roy, 2011)that wives and children are left behind in villages in majority of the rural out-migrant households in eastern India.

Similarly, a huge number of children move with their temporary labour migrant parents. An estimation done by McKenzie (2007)reveals that four out of five migrant children aged 1214 move with their parents. In China, almost a tenth of child population, or 27.3 million children, took part in internal migration with their parents in 2008 (United Nations Children's
Fund, 2010). In India, the number of children migrating seasonally, whether by themselves or with their parents is estimated to be in the range of four to six million (ILO \& UCW, 2010; Smita, 2008). Against these backdrops, this research explores the impact of temporary labour migration of parent(s) on school attendance of the children between 6-14 years and their dropping out from the school through an analysis of the cases from both the ends of migration stream in India. The next section draws on review of literature.

\section{Review of Literature}

Most modern research on migration forms the basis of Ernst Georg Ravenstein's laws on migration (Ravenstein, 1885). In the said context, this research can be put under the law that "most migration is rural to urban" (Ravenstein, 1885). This research however deals with the impact of rural-urban labour migration on education of children. This is because migration has wide-ranging implications on children whether they are left behind by one or both migrating parents, or move with the parents (or born abroad), or migrate alone (UNICEF n.d.). Most of the studies on impact of migration on children's education are conducted in the context of international migration. Micro-level studies in the field of international migration suggest that remitted earnings from international migration positively affect household outcomes including outcomes for children's education (Jones, 1995; Taylor, 1987). In Philippines, children of migrants were found to live in socioeconomically better-off households, attend private schools and engage in extra-curricular activities (Scalabrini Migration Center, 2004).

However, the results from the case studies conducted by UNICEF and SU-SSC in 2006 indicate that the absence of the father often results in increased household responsibilities on children left behind. Also, the children who migrate with the family are at the risk of family labour, risk on street and social exclusion. In Moldova, the absence of the father has little negative consequences on a child's development (Vladicescu et al., 2008). School 
performance of children left behind is often compromised by increased household responsibilities and obligations to care for their younger siblings. Adolescents from left behind households may become labour migrants as part of their transition to adulthood. In a Mexican context where remittance from the USA lowers the likelihood of children labourforce participation and increases resources for consumption of education-related goods (Kandel \& Kao, 2001), 61\% of left behind children still suffered from psychological problems and felt abandoned (UNICEF-UNDP Survey, 2006 cf. UNICEF, n.d.). Similarly, a study on the Caribbean migration and its impact on children by Bakker et al., (2009) find that children who have been left behind as well as taken along are placed in a vulnerable situation thereby, affecting their psycho-social well-being and exposing them to increased risk of poor academic performance as well as interruption of schooling.

Studies conducted in the Caribbean islands (Bakker et al., 2009) and in Mexico (Kandel \& Kao, 2001) on the psychological aspects of left behind children observed a negative impact of the migration of the father on children's behaviour in rural societies. Many children left behind suffer from depression, abandonment and low self-esteem that can result in behavioural problems such as engaging in violence and crime or running away from home. In some cases, these children face a permanent struggle against a sense of low selfworth, insecurity and neglect throughout their childhood and well into their adulthood. They are increasingly subjected to substantive neglect of health and nutritional care, poor academic performance and interruption of schooling due to additional responsibilities at home. However, no such behaviour was reported by mothers in this study which is similar to studies conducted in Pakistan (Gilani 1986; Khan 1991), in Philippines (Arcinas, 1991) and in India (Roy, 2011). A fair proportion of the wives in Thailand (10-25\%) found it difficult to discipline their children without their husbands (Pitayanon, 1986).
Some studies noticed that the impact of the migration of parents on children is relative. Research carried out in Haiti (Amuedo-Dorantes et al., 2008) finds that the effect of remittances on education depends upon the community and services. In a community with access to schools (surveyed in 2000, before the 20002001 economic and political crisis), remittances increased school attendance, while in communities with poorer access to education (surveyed in 2002), school attendance only improved when there was no out-migration from the household, thereby, implying a negative effect of migration on the education of children. On the other hand, in the absence of (quality) educational facilities at destination, it is extremely difficult for seasonal migrant children to re-join the formal education system back at home. This potentially jeopardises individual skill acquisition and human capital formation, and increases the risk of child labour.

According to Smita (2008), seasonal drought and lack of work in villages in India force entire families to migrate for several months every year in search of work merely to survive. Children accompany their parents, and, as a result, dropout rates from school go up. Similarly, there have been situations in Moldova when children leaving the country with their parents have dropped out of school to work in the host country (Vladicescu et al., 2008). A study conducted on the Tripuri tribe of Tripura finds that though educational status of children improves after migration but they do not get adequate facilities to enrol themselves in good schools as the cost of living in the urban areas is very high (Das and Das, 2014).

From the review of literature, two points have become clear: a) most of the literature on this issue pivot around left behind children of international migrants, and very few studies have been conducted to portray the situation of children of internal migrants, and b) the internal labour migrants, owing to poor wage at the destination, remit lesser amount in comparison to the international migrants; hence the situation of their children may not 
improve as much as in the case of children of international migrants. The present paper is an attempt to underpin this research gap by studying the cases of children of internal migrants at the place of origin as well as at the place of destination. The following section discusses the context.

\section{The Context}

In India, under the syndrome of 'pardesh chalo' (let's move to foreign land for livelihood), a huge mass of rural males (more than 100 million) and females (14.4 million) in India move for work each year and spend 1-6 months away from village (NSSO, 2010; Table 15 , p. 235). Such temporary seasonal migrants contribute about $10 \%$ to the national GDP (Deshingkar \& Akter, 2009)but have not got due attention.

The relationship between labour migration and its impact on children's education has been conceptualised and presented in Figure 1. Labour migrants based on their family association and nature of move can be grouped as: (a) seasonal/temporary without-family migrants, (b) semi/permanent with family migrants, and (c) seasonal/temporary with family migrants.

In poor region of eastern India, male migration leaving wife and children behind in the village is a 'culturally accepted' livelihood strategy (group ' $a$ '). This type of migration may play both positive and negative roles on education of left behind children. On one hand, remittances may improve school enrolment/attendance of left behind children, while on the other hand, absence of father may put the children at the risk of poor performance, school dropout, child labour, lack of discipline, etc. However, in some cases (group ' $b$ '), the family members of labour migrants also shift gradually and settle permanently/for long duration at the place of destination/cities. They often become city residents, and children may get opportunity to avail education and other facilities. By contrast, in case of people who are socio-economically most marginalised in villages (particularly tribal), the entire family strives for survival and participates in the migration process (group ' $c$ '). Migration is the ultimate source of their sustenance. They get mainly absorbed in lowpaid menial works of industrial and agricultural sectors, such as brick kilns, salt making, sugarcane harvesting, stone quarrying, construction, plantation and fishing at the place of destination. Since the nature of work is seasonal and temporary, these families, including children, keep on oscillating from their villages to one or different other destinations. The children remain at the stark.

Thus, when the survival of a family is disrupted and put to question, it is imperative to understand the vicious cycle of poverty, migration and illiteracy. The present paper is an attempt to understand the relationship in the Indian context where studies on the impact of temporary migration on children are few and far between.

\section{Datasets}

A study on distress migration and its impact on education of the children may be conducted by analysing two situations: first, when the father migrates and children are left behind in the truncated family in village, and second, when children accompany their parents who have no fixed place of destination. For the former case, data was collected from 354 migrants and 192 non-migrant households from nine villages of the Bihar state in the year 2001. Bihar was selected for the origin-based study because it registers highest male net out-migration (3.03 million) from the state (Census of India 2001).Villages are structurally very poor and are sustained on agriculture and remittances. Children of non-migrant households were taken 


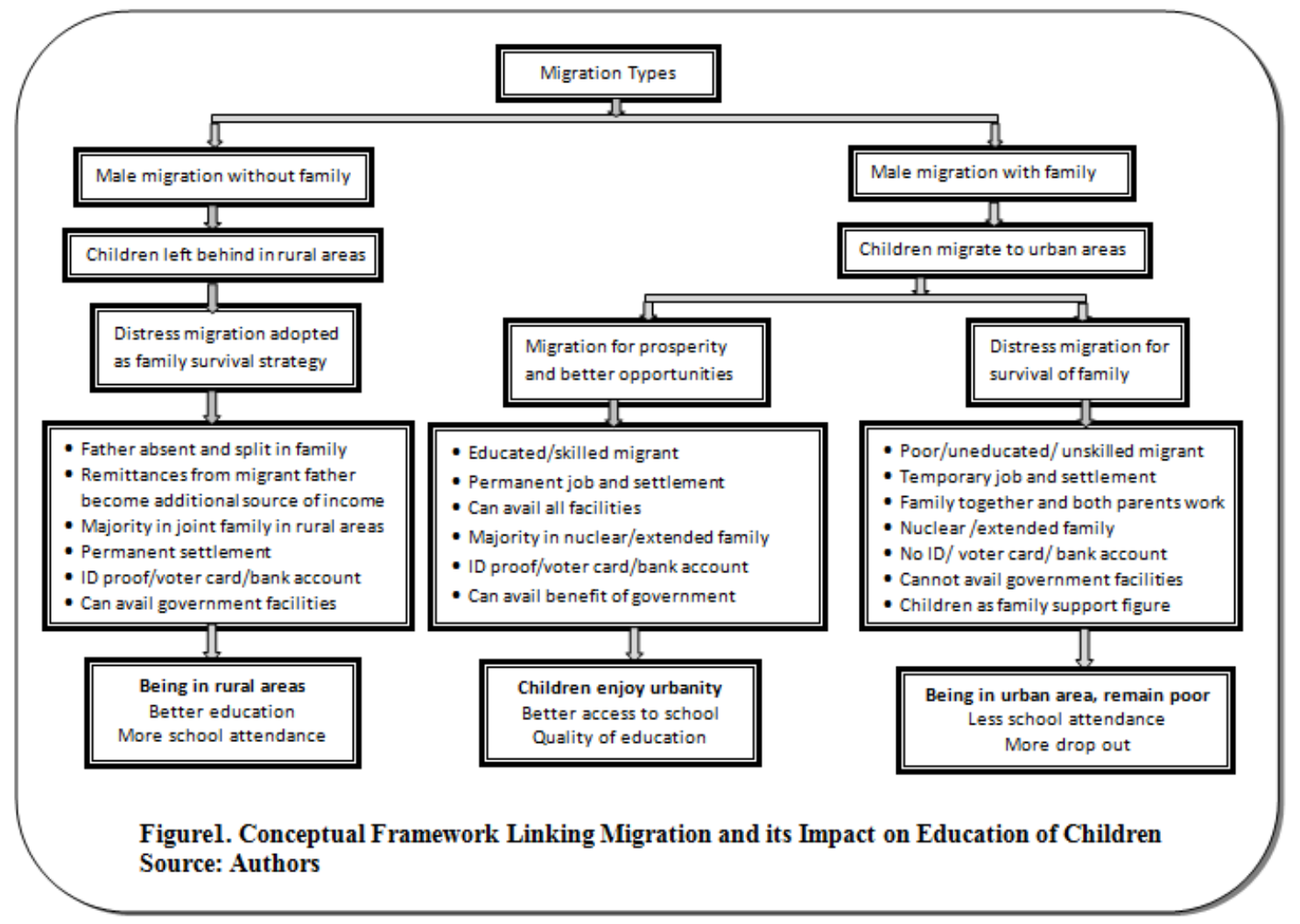

here as a control group to assess the impact of migration on left behind children.

For the latter case, dataset is based on information collected from 49 households working at 13 construction sites of the Varanasi city in 2011. Migrants at construction sites were selected because construction is a fastgrowing, labour-intensive industry, which is being supplied by rural-urban migrants. Due to seasonal nature (remains off during rainy season) of work and temporary nature of construction industry, the labourers become 'footloose workers' and they keep changing their sites very often either with the contractor (in the same or different cities) or on their own.

It is pertinent to mention here that these two cases are micro-level studies and are conducted in two different times. However, both the study areas are located in the same socio-cultural settings of eastern UP and western Bihar, which have not undergone any major socio-economic transformation during the last decade (Planning Commission, Gol, 2003). Hence, the datasets may be compared with each other to analyse the process and impact of migration. Both studies were based on quantitative and qualitative techniques of data collection. School enrolment of children in 6-14 age groups is used as a dependent variable to measure education outcomes. To understand the reasons for non-enrolment and dropout from school at the regional level (eastern UP and western Bihar)large-scale District Level Health Survey 3 (DLHS 3) data was used.

\section{Results and Discussion}

\section{Migration Scenario}

Before getting into the aspect of children's education straightaway, it is necessary to highlight the background characteristics of distress labour migrants. In the villages of Bihar, migration for seeking employment is a predominant feature. $60 \%$ of total 2,724 
households were migrant households, from where 2,250 males have migrated for employment. Approximately, $80 \%$ have migrated to agriculturally and industrially developed north and north-western states of the country. Half of them have moved without families, and the figure goes higher in the case of poor and landless Muslims, Scheduled Castes and Backward Castes people. ${ }^{1}$

At the place of destination, at the construction sites in Varanasi, it is evident that out of a total of 377 migrants, $60 \%$ were inter-state migrants (mainly from the states of West Bengal and Jharkhand) and remaining were intra-state migrants from the neighbouring districts of Varanasi (Table 1). About three-fourths of them were single male-migrants and the remaining 102 labourers had moved with their families, comprising 49 migrant households. Threefourths of the with-family migrants were Muslims from West Bengal (39\%), Scheduled Caste and Scheduled Tribe (27\%) groups. It is to be noted that the Muslim labourers from Bihar and Jharkhand were the single male-migrants, who moved without families. The exploration of such reasons is out of purview of this study.

\section{Life and Living Arrangement of the Migrant's Families}

Migration provides subsistence to the workers and their families, but exposes them to a harsh and vulnerable existence, in which working and living conditions are poor (Srivastava, 2012).

\footnotetext{
1 Indian society is divided into more or less exclusive hierarchical groups whose membership is ascribed on the basis of parental membership at birth and have been assigned power, rights and role to perform in society. Scheduled Castes (SCs) and Scheduled Tribes (STs) are among the most disadvantaged socio-economic groups in India.

Article 366 (25) of the Constitution of India refers to Scheduled Tribes as those communities, who are scheduled in accordance with Article 342 of the Constitution. The essential characteristics, first laid down by the Lokur Committee, for a community to be identified as Scheduled Tribes are: indications of primitive traits; distinctive culture; shyness of contact with the community at large; geographical isolation; and backwardness (Ministry of Tribal Affairs, Gol, http://tribal.nic.in/Content/IntroductionScheduledTribes .aspx).
}

Tables 1 and 2 exhibit the socio-economic characteristics and income of migrants. Migrants in both the case studies comprise the most vulnerable sections of society. Nine out of 10 households belonged to the Backward Castes, Scheduled Castes and Muslim communities, and eight out of 10 migrant households were landless or possess less than an acre of land. Majority of them were either illiterate or semi-literate (approximately $80 \%$ at the construction site and $40 \%$ in the village case) and were engaged in low-paid jobs in the informal sector. ${ }^{2}$ These Jobs are not permanent hence, labourers oscillate from the place of origin to different destinations. For example, at the construction sites at Varanasi, the current work site for 27 of 49 migrants' families was reported as 3rd or 4th destination.

The average remittance received by migrant households in the study villages was very meagre, just ₹13,391 (approx. US\$ 280) per annum in 2001 (Table 2) which is quite closer to the NSSO 64th round (NSSO 2010, Table 15, p. 170) figure for Bihar (₹15,148 or approx. US\$ 304), including remittances from international migrants). At the place of destination, the entire family of the migrant is engaged and work under the banner of one contractor. The average wage of migrant workers was just ₹ 162 (approx. US\$3) per day for eight hours of work (Table 1). Wages of the females were lower than that of their male counterparts for the same kind of work (₹30 less than single migrants), which is a serious violation of Equal Remuneration Act, 1976, Government of India. ${ }^{3}$

\footnotetext{
2 The term 'informal sector' had been coined by a British anthropologist, Keith Hart in 1971. According to NSS (55th round), the informal sector can be described as the mass of people seen on the streets and sidewalks and back allies of cities, including petty traders, street vendors, coolies and porters, and small artisans, messengers, barbers, shoeshine boys and personal servants.

3 Equal Remuneration Act, 1976 [Act 25 of 1976 amended by Act 49 of 1987] is an act to provide for the payment of equal remuneration to men and women workers and for the prevention of discrimination, on the ground of sex, against women in the matter of employment and for matters connected therewith or incidental thereto.
} 


\section{Table 1: Characteristics of Migrants at the Place of Destination}

\begin{tabular}{|c|c|c|c|c|}
\hline $\begin{array}{c}\text { Socio-economic and } \\
\text { Demographic } \\
\text { Characteristics }\end{array}$ & $\begin{array}{c}\text { Percentage of } \\
\text { without-family } \\
\text { migrants }\end{array}$ & $\begin{array}{c}\text { Percentage of } \\
\text { with-family } \\
\text { migrants }\end{array}$ & $\begin{array}{l}\text { Total No (in } \\
\text { percentage) }\end{array}$ & $\begin{array}{l}\text { Mean wage } \\
\text { (in ₹) }\end{array}$ \\
\hline \multicolumn{5}{|l|}{ Family } \\
\hline Single migrant & - & - & - & 169 \\
\hline With family migrant & - & - & - & 140 \\
\hline \multicolumn{5}{|l|}{ Sex $* * *$} \\
\hline Male & 95 & 54 & $316(84)$ & 170 \\
\hline Female & 5 & 46 & $60(16)$ & 113 \\
\hline \multicolumn{5}{|l|}{ Caste/community*** } \\
\hline SCs & 51 & 18 & $158(42)$ & 166 \\
\hline STs & 14 & 27 & $65(18)$ & 123 \\
\hline $\mathrm{BCs}$ & 17 & 12 & $59(16)$ & 174 \\
\hline General & 1 & 3 & $5(1)$ & 179 \\
\hline Muslims & 17 & 39 & $87(23)$ & 173 \\
\hline \multicolumn{5}{|l|}{ Educational level } \\
\hline Illiterate & 56 & 62 & $199(58)$ & 156 \\
\hline Primary & 19 & 18 & 65 (19) & 170 \\
\hline Middle & 12 & 16 & $44(13)$ & 174 \\
\hline High school & 9 & 4 & $27(8)$ & 194 \\
\hline Intermediate & 4 & 0 & $10(3)$ & 205 \\
\hline Graduate & 0 & 0 & $1(0.3)$ & 150 \\
\hline \multicolumn{5}{|l|}{ Occupation type $* * *$} \\
\hline Mason & 23 & 23 & $157(23)$ & 232 \\
\hline Labour & 59 & 75 & $65(63)$ & 126 \\
\hline Painter & 2 & 0 & $59(2)$ & 250 \\
\hline Carpenter & 6 & 1 & $87(5)$ & 176 \\
\hline Fitter & 9 & 1 & $5(7)$ & 197 \\
\hline Water proofing & 1 & 0 & $1(1)$ & 300 \\
\hline \multicolumn{5}{|l|}{ Place of origin*** } \\
\hline Uttar Pradesh & 47 & 24 & $152(40)$ & 175 \\
\hline Bihar & 18 & 8 & $58(15)$ & 150 \\
\hline Jharkhand & 16 & 23 & $67(18)$ & 146 \\
\hline West Bengal & 18 & 26 & $76(20)$ & 152 \\
\hline Madhya Pradesh & 1 & 11 & $13(3)$ & 175 \\
\hline Chhattisgarh & 0 & 7 & $8(2)$ & 133 \\
\hline Total & $275(73)$ & $101(27)$ & $376(100)$ & 162 \\
\hline
\end{tabular}

Migrants at the construction site live in a single-roomed temporary dwelling made of bricks and tin sheets. Each one was given one electric connection for lighting and they need to share common drinking water supply and toilets temporarily arranged by the contractor. They use firewood as cooking fuel, which is collected locally by the children of the migrants or even the migrants themselves. 28 of them had mobile phones. Each migrant worker at the construction site gets a partial payment of ₹ 300-400 (approx. US\$ 5.5 to 7.3) per week from their salary called as Khuraki by the contractor for the purchase of food items only. The bulk salary or the balance of the salary is 
paid to them when they finally move after 5-6 months or sometimes even after a year or so.

\section{Children of Migrants}

Age-sex structure of left behind families at the place of origin and migrant families at the place of destination seem to be complementary to each other [Figures 2 (a) and 2 (b)]. However, the broader pyramid base at the place of origin indicates that large numbers of children are left behind in villages by their migrating fathers. There were a total of 1,294 left behind children from 354 migrant and 682 children from 192 non-migrant households below the age of 15 , of which $67 \%$ and $69 \%$ were in primary-schoolgoing-age group (age 6-14) respectively. At the construction sites, there were a total of 91 children in the age group of $0-14$ out of 49 migrant families, and $60 \%$ (55) of them were in primary-school-going-age group.

\section{Table 2: Mean Remittances Received by Migrant Households by Background}

\section{Characteristics}

\begin{tabular}{lcc} 
Background Characteristics & No. of Households & Mean Remittances(in ₹) \\
\hline Landholding size & 278 & 12649 \\
$<1$ acre & 41 & 15780 \\
$1-3$ acre & 25 & 17720 \\
$\geq 3$ acre & & \\
Caste group & 46 & 16587 \\
Upper caste & 157 & 12934 \\
Backward caste & 61 & 10374 \\
Scheduled caste & 80 & 14750 \\
Muslim & & \\
Family Type*** & 259 & 13926 \\
Joint & 85 & 11714 \\
Nuclear & & \\
Household Size*** & 139 & 11335 \\
$\leq 5$ & 149 & 13941 \\
$6-10$ & 56 & 17029 \\
$\geq 11$ & & \\
No of migrants in a HH** $^{* * *}$ & 9915 \\
1 & 201 & 17378 \\
2 & 89 & 18441 \\
3 & 37 & 22624 \\
4 & 17 & 13391 \\
\hline
\end{tabular}

$\begin{array}{lll}\text { Total } & 344 & 13391\end{array}$

\section{Chi-square significance level $* p<0.05 * * p<0.01 * * * p<0.001$}

\section{Source: Fieldwork, 2001}

\section{Education of Children}

Migration directly (through remittances) or indirectly (through knowledge, attitude and practice) foster educational attainment among left behind children. The expenditure pattern (Figure 3 ) in village households indicates that majority of remittances are spent on meeting necessary cost, including agriculture (37\%), food $(16 \%)$, health $(30 \%)$, clothing $(12 \%)$, education (3\%) and others (2\%). The share of income on education was though minimal (3\% of income) but it was higher than non-migrant family's share (2\% of income). Moreover, $70 \%$ of the migrant households used remittances for educating their children (please refer to Picture-Set 1 which portrays village children in village schools in the study area). There was no difference in the level of school attendance of boys in migrant and non-migrant households. However, educational gain was much higher for 
left behind girls (75\%) than girls of nonmigrants (50\%) were (Figure 4). Thus, migration not only improves the educational attainment but also leads to the reduction of gender gap in access to school.

However, migration may not necessarily connect all left behind children to education particularly when this strategy is adopted by the poorest of the poor. 24 out of every 100 left behind children were out of school at the time of the survey. Case study of Bhola (fictitious name) is one of such stories, which clearly illustrates how children of migrants are trapped by the cycle of poverty and migration.
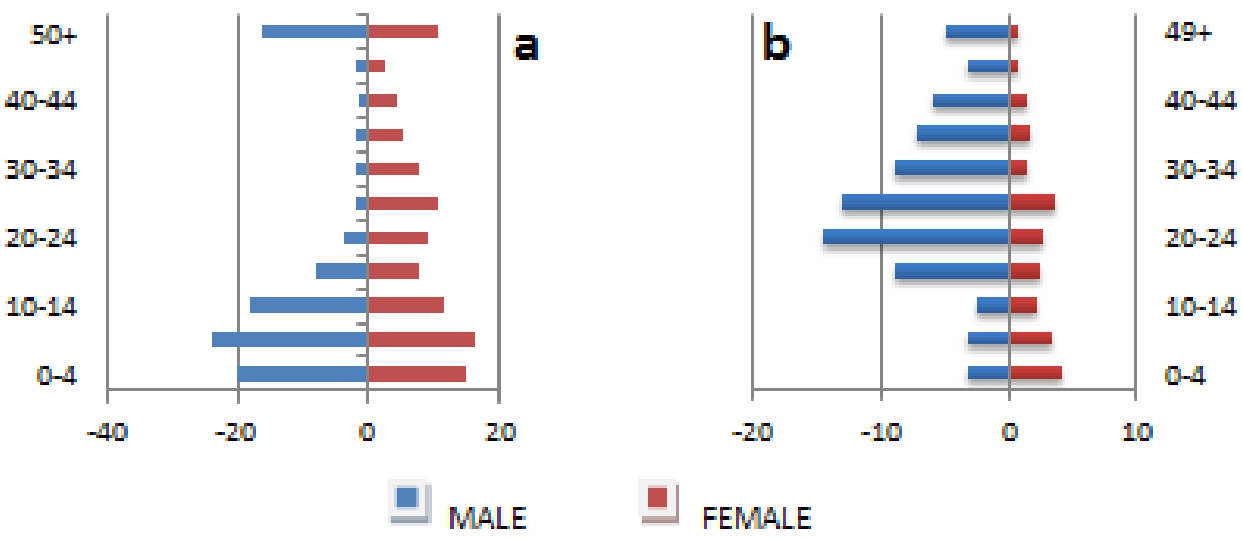

FEMALE

Figure 2(a). Age-sex Structure of Migrant Families at the Place of Origin in Bihar based on 2001 Field Data and Figure 2(b). Age-sex Structure of Migrants at the Place of Destination in Varanasi based on 2011 Field Data.

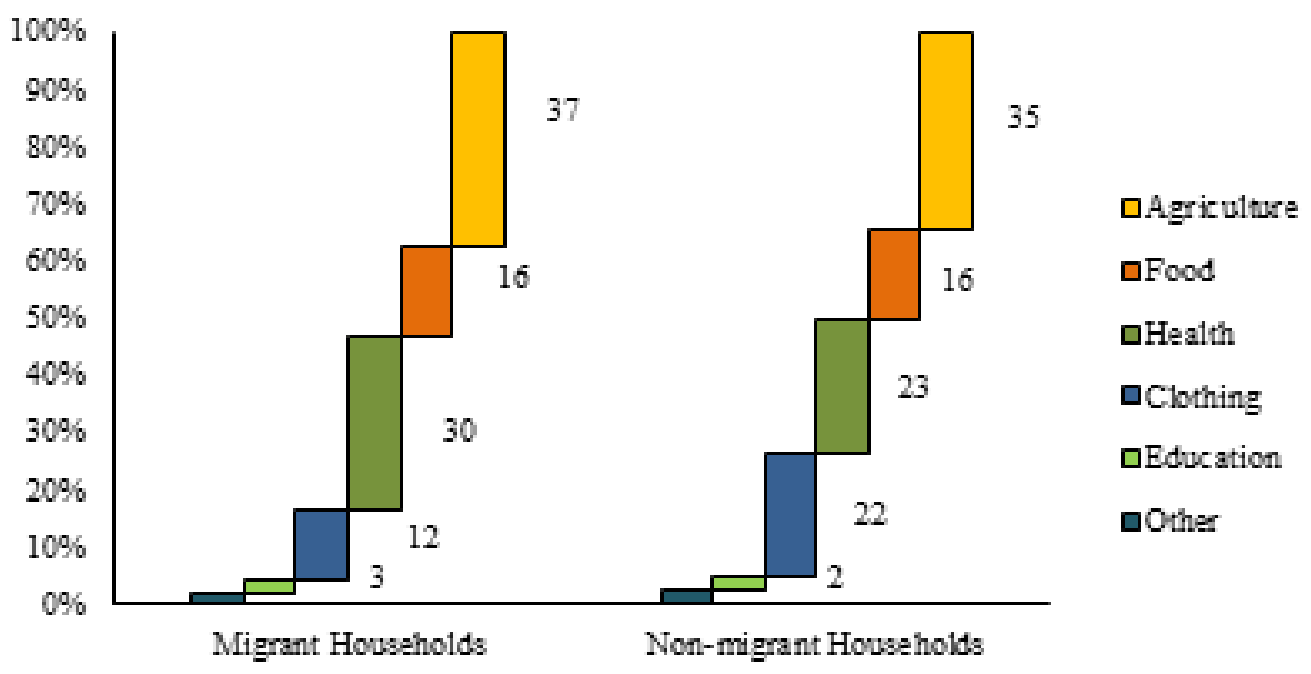

Figure 3 Expenditure Pattern in Migrant and Non-migrant Households at the Place of Origin, Bihar

Source: Fieldwork, 2001 

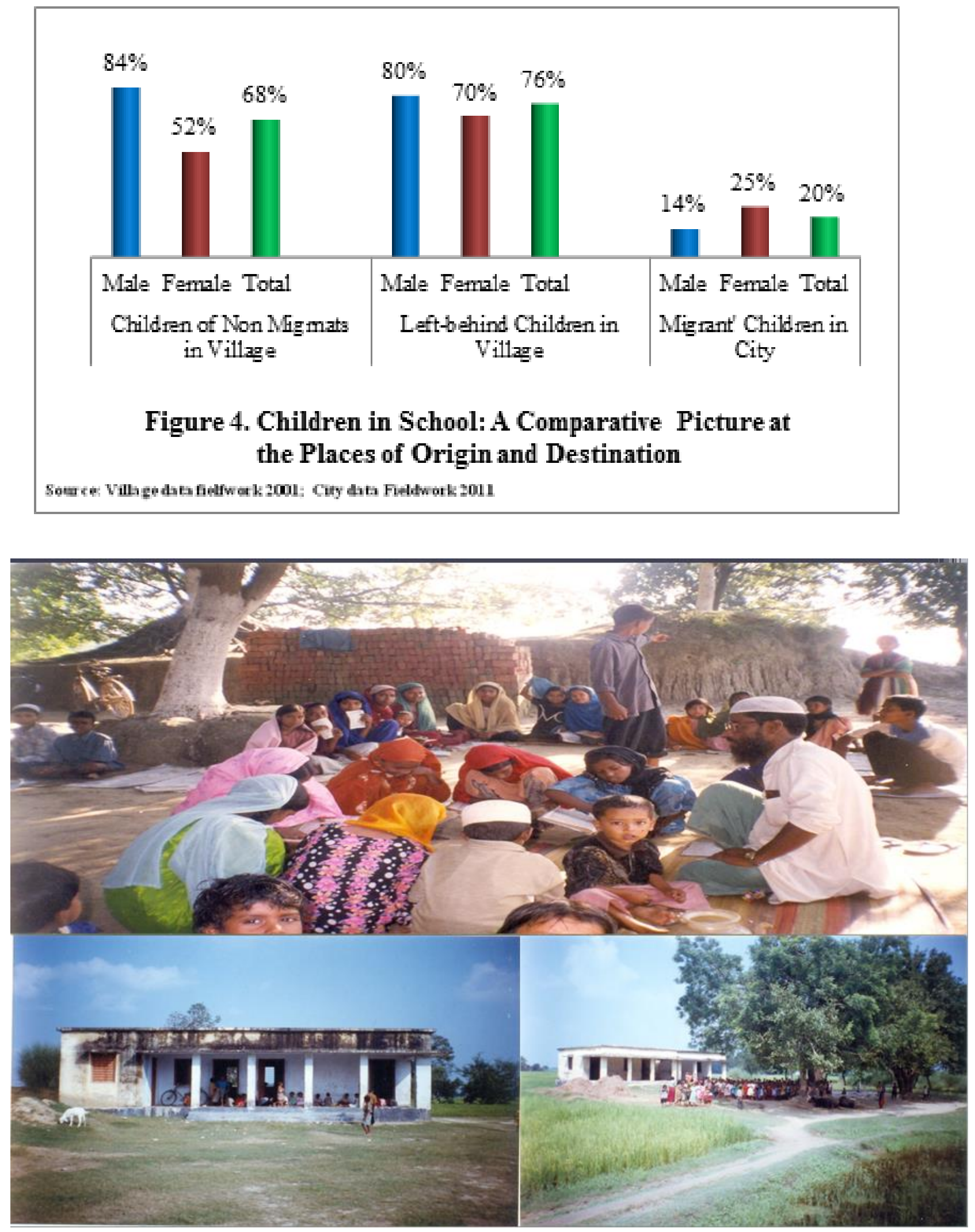

Picture-Set 1: Children in Madarsa/School in Villages (Courtesy of the Authors)

Case 1: An Old Experienced Migrant (Bhola60 years, SC, Uttar Pradesh, wage ₹ 110)

Bhola is an experienced migrant labourer found working at one of the construction sites of Varanasi. He works along with his two sons and two daughters-in-law. He entered into the labour force right at his childhood. In the past 50 years, he had been migrating without families and worked in various jobs as a helper in a truck, an auto driver, a porter, and so on. He had visited many cities for livelihood like 
Mumbai, Delhi, Lucknow, Surat, etc. He spent all his earnings in bringing up his five children and arranging dowry for his daughters' marriages. Although he worked for his entire life, he could not save any penny to build his own house for permanent stay. Irony of his earning is that none of his children could get education.

At the place of destination, out of 91 children, 55 were in primary-school-going age and only 34 eligible children had ever been to school. School attendance for 'migrant' children at the place of destination was very stumpy (Figure 4). Only 11 children ( 4 boys and 7 girls) were attending school at the time of the survey. Seven of 11 children attending school (5 in Hindi-medium government school and 2 in English-medium private school) were actually left behind and living in villages with their grandparents or relatives for their studies. The four who were attending school at the place of destination were from Muslim families whose parents have strong will power to educate their children and include them in the mainstream of development. The research also reveals that since children were of tender age, they often come along with their parents' at the workplaces for a short duration on some occasions; and though their stay is for a brief period, their studies get interrupted and gradually they drop out of school and enter into labour force.

\section{Educational Performance of Children}

The impact of migration on school attendance of left behind children was largely positive; but poor performance in studies, indiscipline and disobedience among children cannot be ruled out in some of the cases. The impact of fathers' absence on the education of children was also assessed in terms of children's performance in school and their behaviour. Poor performance in school, disobedience and bad habits of children were reported more by the mothers of left behind children $(33,41,1.8 \%)$ than the mothers of non-migrant children $(15,23,0.6 \%)$ (Figure 5). Mothers had general opinion that remittances enabled their children to attend school, but on the other hand, children do not listen to their mothers and tended to become undisciplined and disobedient due to the absence of their fathers.

However, no negative impact of fathers' migration on the psychological aspects of left behind children was reported which probably may be due to the joint family system and larger family size prevailing in rural societies, which works as a support system for the left behind children.

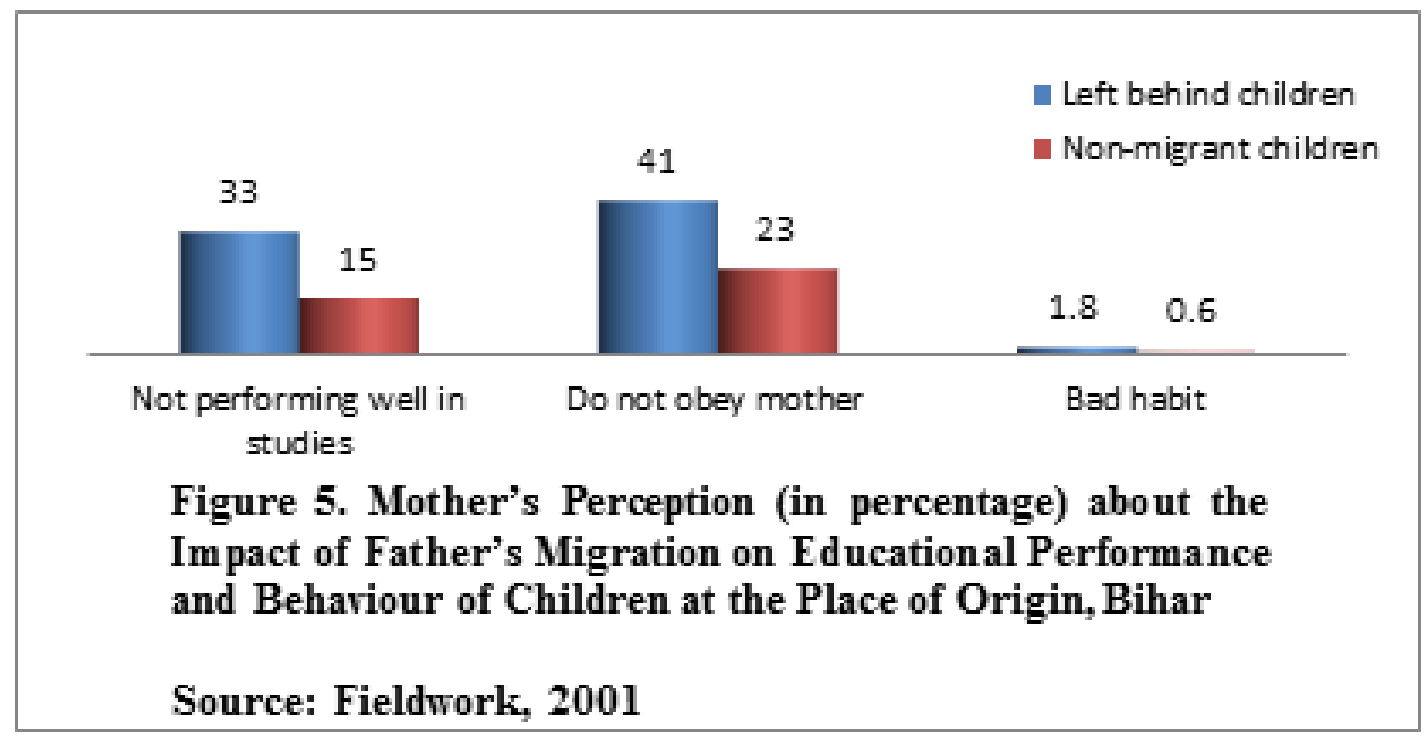




\section{Aspiration of Parents about Educating Children}

Questions were asked to know the attitudes of parents towards the education of their children at the place of origin and destination. All parents at the construction site replied that the education is necessary, but ironically, $80 \%$ of their children could not be put into school. Parents were asked up to what level they would like to educate their children. Their aspirations were quite low. The common response was that basic literacy would be enough for their children, which may enable them to make signature, read and write addresses and phone numbers. The majority had no aspirations and motivation about the education of their children.

Similarly, in villages, the mothers of left behind children had a strong desire to educate their children, but the level to which they wished to provide education to their girls and boys differed. In general, half of the mothers expressed their desire to make their girls literate. In addition, $46 \%$ of non-migrant girls' mothers compared to $39 \%$ of left behind girls' mothers wanted to educate them up to the secondary level. In the case of boys' education, the majority of the mothers (under both the categories) said there is no limit and that they (sons) may study as much as they wish to, and this proportion was higher in the case of left behind children's mothers. The qualitative observations suggest that discrimination between boys and girls attributed to the feeling of insecurity in sending their grown-up daughters to far-off schools. The feeling of vulnerability was higher among left behind children's mothers as it would become difficult for them to keep a watch on their daughters in the absence of their fathers.

\section{Why are Children out of School?}

The study finds that the migration of father connect the left behind to school as 24 out of every 100 left behind children, 32 out of every 100 non-migrant children were out of school. But when children accompany their mobile parents, they get disconnected from the school, and 80 out of every 100 such children remained out of school at the time of the survey. Data was analysed to examine the reasons for children being out of school, comprising those left behind at the places of origin; accompanying migrant children at the place of destination as well as at the regional level (in eastern UP and western Bihar) using large-scale DLHS 3 data. As per DLHS 3, in this regional level, 24 out of 100 children in the age group of 6-11 years have never been to school in 2004. This is despite the launch of various educational programmes like the District Primary Education Programme (DPEP since 1992), ${ }^{4}$ Minimum Levels of Learning $(\mathrm{MLL})^{5}$ initiative, National Programme for Universal Elementary Education (Sarva Shiksha Abhiyan $)^{6}$ by the Indian government.

A linear regression was run to understand factors responsible for school attendance by left behind children in the migrant-sending villages (Table 3 ). The model explains only $29 \%$ of the variation in the dependent variable, that is, all children go to school. The chances of all children attending school reduces if standard of living of family is low, number of siblings are more and mother is needed to work as a labourer to support family (at $95 \%$ confidence). In such poor families, children do drop out from

\footnotetext{
${ }^{4}$ District Primary Education Programme (DPEP) (External website that opens in a new window) was launched in 1994 as a major initiative to revitalise the primary education system and to achieve the objective of universalisation of primary education.

${ }^{5}$ The basic concern of Minimum Levels of Learning (MLL) is that irrespective of caste, creed, location or sex, all children must be given access to education of a comparable standard. The major focus of the policy formulation behind the MLL exercise is upon equity and reduction of existing disparities.

${ }^{6}$ The Sarva Shiksha Abhiyan (SSA) launched in 2000 is a historic stride towards achieving the long cherished goal of Universalisation of Elementary Education (UEE) through a time-bound integrated approach, in partnership with state. SSA, which promises to change the face of the elementary education sector of the country, aims to provide useful and quality elementary education to all children in 6-14 age group by 2010.But the Government of India recognised education as a fundamental right for all children in the age group of 614 years and thereby, the Parliament passed the Right of Children to Free and Compulsory Education (RTE) Act, 2009 that came into effect on 1 April 2010.
} 
school to take up family responsibilities. Picture-Set 2 demonstrates the types of unpaid jobs that the children perform for their families - the upper three pictures illustrate their works in the villages and the lower three in the construction sites. The findings observed in this research thus mirror those of the previous studies that have examined children's unpaid work by Dyson $(2008 ; 2014)$ in the
Bemni Village, located in the high Himalayas of Uttarakhand. Further, this research also explicate that girls act as little mothers when the mothers are busy with other chores and young boys attend to their cattle in the absence of their fathers (Jetley, 1987; PROBE, 1999; Bhattacharyya and Vauquline, 2013).

\section{Table 3: Model of Linear Regression Showing Determinant of Left Behind Children being Out-of-School, Bihar}

Dependent variable: All children go to school

\begin{tabular}{cc}
\multicolumn{2}{c}{ Unstandardised coefficients } \\
\hline B & Std. Error \\
\hline 2.291 & .238 \\
-.089 & .098 \\
-.197 & .063 \\
-.111 & .018 \\
-.019 & .029 \\
.013 & .064 \\
-.042 & .057 \\
.011 & .006
\end{tabular}

(Constant) ${ }^{* * *}$

Mother alone in family

Mother work for wages***

$-.197$

Total number surviving children***

.111

Caste

$-.019$

Average remittances

$-.042$

District

.011

.006

Adjusted R Square: 0.291.

Significance level $* \mathrm{p}<0.05 * * \mathrm{p}<0.01 * * * \mathrm{p}<0.001$

\section{Source: Fieldwork, 2001}
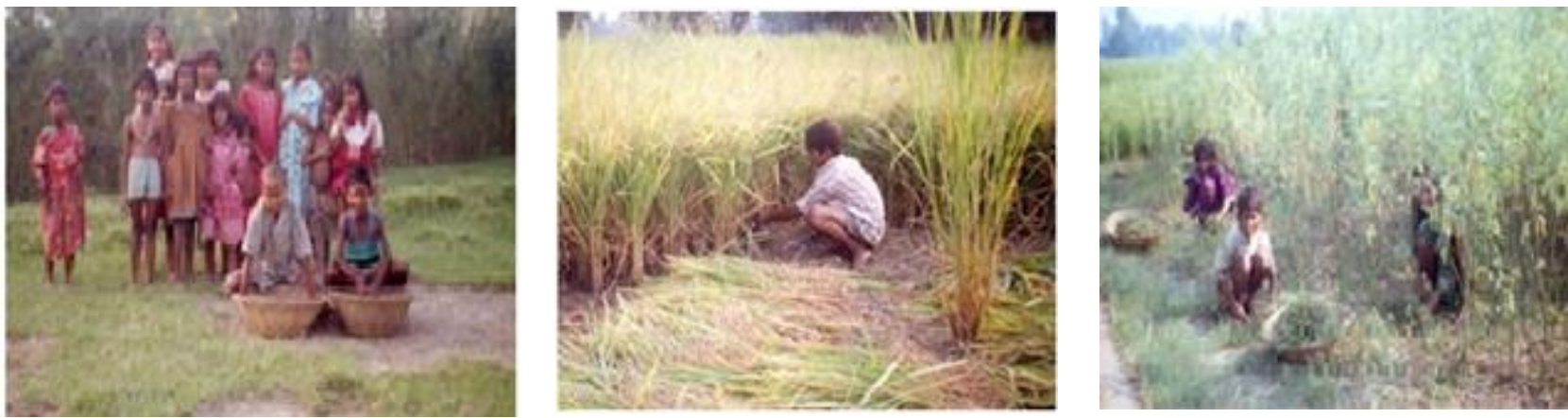

Out of School Children (in Villages) engaged in unpaid activities
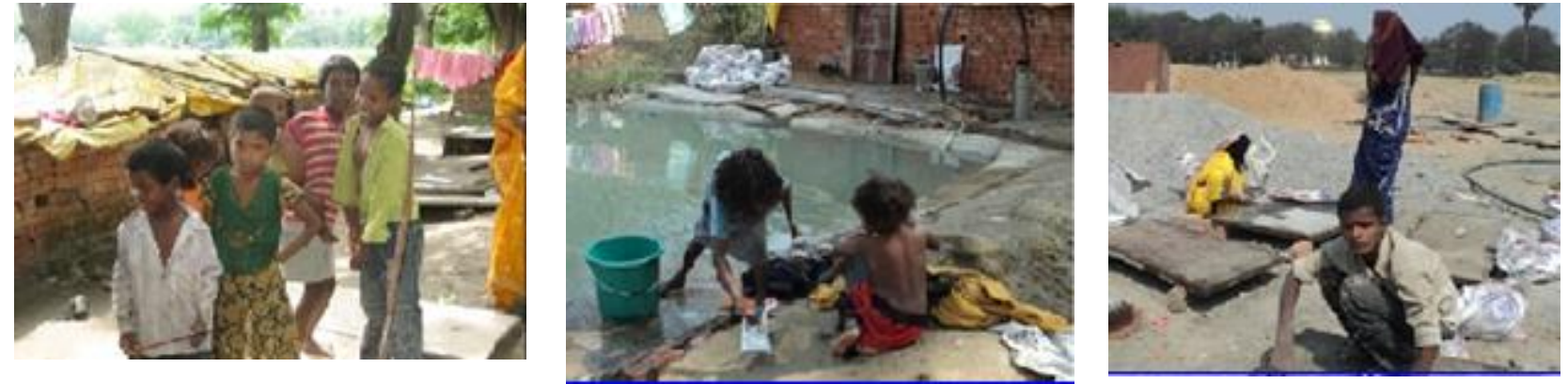

Out of School Children (at Construction Sites) engaged in unpaid activities

Picture-Set 2: Children engaged in various unpaid works (Courtesy of the Authors) 
In contrast, there is a peculiar situation for accompanied migrant labourers who belong neither to their villages nor to the destination areas. They forego the government welfare benefits in their villages and cannot access these at the migration sites either. Nonattendance $(80 \%)$ and dropout rate $(32 \%)$ of children were quite higher compared to their left behind children of villages and the regional average (Figure 4). The majority of the children in the migrant families were out of school mainly due to poverty, frequent change in work place, lack of knowledge about school and admission procedure, and unavailability of child-care facilities at the construction sites. They support their parents by looking after their younger siblings, cooking food and collecting fuel wood when both parents go to work. The physical access to school is the crucial point for the accompanied children. Some parents said that their children are bound to move with them due to the lack of social support available in the villages, hence, they are dropped out of school (Case No 2).

\section{Case 2: Widow Tribal Woman(aged 35 years from Jharkhand, wage ₹ 110)}

Paras Mani (fictitious name) is a tribal widow from Gumla, Jharkhand, one of the poorest states of the country. She works as a construction labourer at Varanasi along with her 14-year-old daughter, Goltu Soren. Her husband expired in 2009. Although she had 8 acres of agricultural land at her native place, but it remains barren/fallow due to lack of irrigation facility. She had also taken loan and was unable to pay back due to poverty. The grim situation forced her to migrate with her daughter, Goltu (14), and son, Bantu (6). They came to Varanasi with an agent. Her daughter used to go to school before migration but now she works with her mother at the construction site. Paras Mani wanted to educate her son but she was unaware about any school nearby to the current working site.

The case of Paras Mani highlights that availability of assets at the native place does not guarantee that people will not migrate. After the death of her husband, Paras Mani had to migrate with her children in spite of having eight acres of land. The land was uncultivable due to the lack of irrigation facilities, and thus she was unable to undertake agricultural activities for earning her livelihood. The story of exploitation of migrant labourers, especially in the tribal pockets of Jharkhand and Chhattisgarh, begins at the village level itself. The family members of the labourer get some debt from the broker to meet their day-to-day personal expenditures. When the loan amount becomes substantial of ₹3000-4000 then the local brokers hire their children and family members and take them away to various places of work outside the state. It is also mentioned by van de Glind (2010) that in the absence of (quality) educational facilities at destination or transfer certificates whenever schooling opportunities do exist, it is extremely difficult for seasonal migrants' children to re-join the formal educational system.

Children in these families are the support figures for the poor migrant parents directly by helping parents at the construction site or indirectly by caring for the younger siblings, cooking and collecting firewood for cooking. Srivastava (2012) finds that when migration takes place as a family unit, each member of the family unit, excluding infants, contributes to family subsistence in one way or another in work or as a part of the household 'care' economy. For the poor migrant parents, making both ends meet becomes their priority rather than educating their children.

Now it is worthwhile to understand the overall situation of non-enrolment and dropout in and from school at the regional level. The reason behind 'never enrolled in school for primary school age-group children' was enquired in DLHS 3 (Figure 6). Poverty/economic reason were reported by one-fourth of the parents as the main factor for non-enrolment and dropout of the children in this region. Apart from reporting poverty as a direct factor, lack of interest in studies for boys and households chores (caring for siblings, cooking, managing household work and managing family business) for girls were other important reasons for 


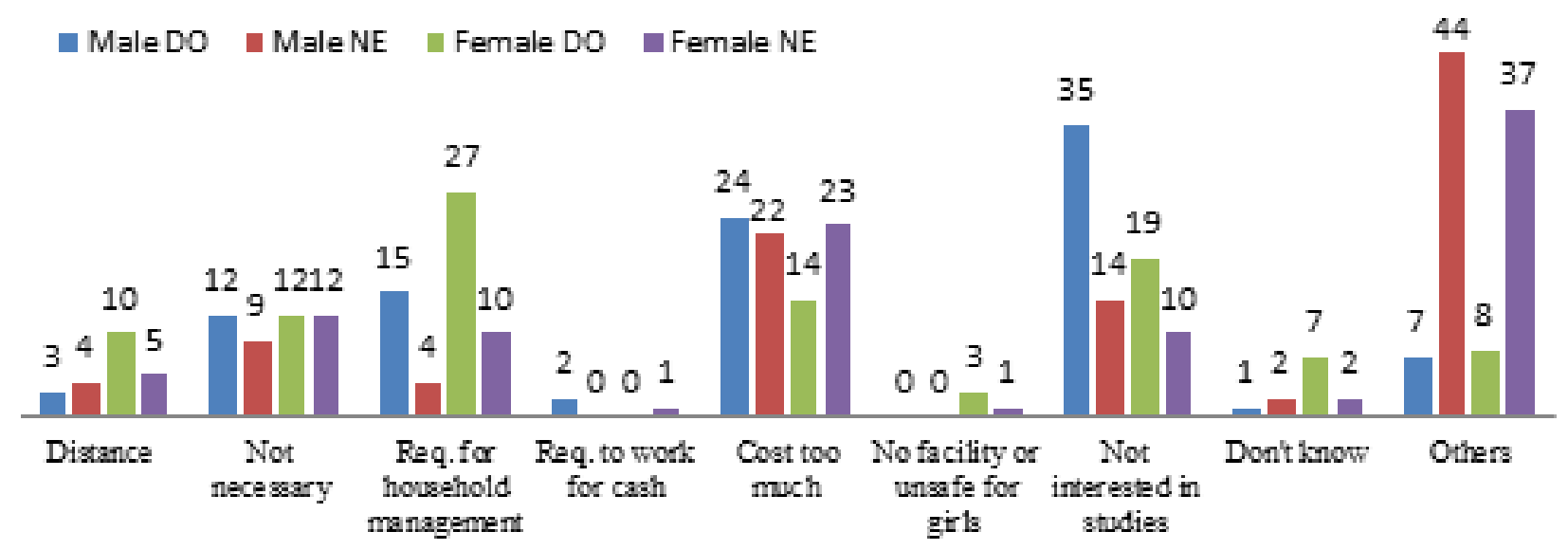

\section{Figure 6. Gender-wise Percentage Distribution of Children by Reasons for School Non-enrolment (NE) and School Dropour (DO) in Western Bihar and Eastern Uttar Pradesh, DLHS 3}

dropout. Some additional reasons for girls' dropping out of school were reported as distance of school, girl's safety and the lack of civic facilities at school (13\%).

\section{Conclusions}

The seasonal labour migrants, whether they move alone leaving their families behind or move with families, all belong to vulnerable sections of the society. Their jobs are not permanent and they are bound to oscillate from the one place of origin to different destinations. In case of left behind families, remittances are additional source of income for them; while at the place of destinations, whole family of the migrant are engaged to work for survival. They earn lower wages. The case studies of 60-year-old man and a tribal widow unearth many aspects of distress labour migration and its linkage to poverty, indebtedness, migration and exploitation at various levels.

Remittances received by the left behind families have a positive impact on the education of children. It reduces the gender gap in school enrolment and lowers the school dropout rate. Thus, migration contributes to the checking of child labour. This finding is similar to the findings of World Bank (2007) and
IOM studies (2006). In addition, education of children becomes dismal when they migrate along with their parents in oscillating type of jobs.

In both case studies (left behind and migrant children), the common cause of concern is the situation of poverty prevailing in both of them equally. When both parents at the place of destination and origin take the role of bread earners, then the hearth is looked after by the young kids, particularly the girls of the family. Children's involvement in household activities becomes a practical necessity. They work as little parents and 'deputy home managers' in the absence of their parents and thus remain out of school. They are always on the verge of dropping out whenever the parents change their work site or children get distracted from education in the absence of their parents.

Concisely, migration can provide a temporary relief from poverty but it does not give a permanent solution. It raises many questions like how the needs of these distressed people can be addressed and how these children can be connected and mainstreamed into the education system. There is an urgent need to mainstream migrants' children through formal or non-formal educational systems encompassing their right to education. Imparting the right education and skills only 
can help them to break the vicious cycle of poverty and to lead a dignified and meaningful life.

\section{References}

Amuedo-Dorantes, C., Pozo, A. G., \& S. Pozo (2008). Migration, Remittances and Children's Schooling in Haiti. Discussion Paper No. 3657. Bonn, Institute for the Study of Labour.

Arcinas, F. R. (1991). Asian Migration to the Gulf Region: The Philippines Case. In G. Gunatilleke (Ed.), Migration to the Arab Experience of Returning Migrants (p. 134). Tokyo: United Nations University.

Bakker, C., Elings-Pels, M., \& Reis, M. (2009). The Impact of Migration on Children in the Caribbean.

Bhattacharyya, R. \& Vauquline, P. (2013). A Mirage or a Rural Life Line? Analysing the Impact of Mahatma Gandhi Rural Employment Guarantee Act on Women Beneficiaries of Assam. Space and Culture, India, 1:1. Retrieved from

http://www.spaceandculture.in/index.php/spa ceandculture/article/view/10/1

Bryant, J. (2005). Children of International Migrants in Indonesia, Thailand, and the Philippines: A Review of Evidence and Policies, (April). Retrieved from https://gfmd.org/documents/brussels/gfmd_br ussels07_contribution_unicef_irc_report_childr en_of_migrants_en.pdf

Das, S. \& Das, M. (2014). Income, Migration and Social Adjustment of the Tribal People in Tripura: A Case Study of the 'Tripuri' Tribe. Space and Culture, India, 2014, 2:1. Retrieved from

http://spaceandculture.in/index.php/spaceand culture/article/view/60/pdf_14

Deshingkar, P., \& Akter, S. (2009). Migration and Human Development in India. UNDP Human Development Research Paper, (2009/13).

Dyson, Jane (2014).Working Childhoods: Youth, Agency and the Environment in India. Cambridge, United Kingdom: Cambridge University Press
Dyson, Jane (2008). Harvesting Identities: Youth, Work, and Gender in the Indian Himalayas, Annals of the Association of American Geographers, 98:1, 160-179, DOI: 10.1080/00045600701734554

Gilani, I. S. (1986). The Left Behind Families. In M.A. and Y. Atal (Ed.), Middle East Interlude: Asian Workers Abroad. Bangkok: United Nations Educational, Scientific, and Cultural Organisation.

ILO \& UCW. (2010). Joining Forces against Child Labour: Interagency Report for the Hague Global Child Labour Conference of 2010 (p. 58). Geneva.

International Organisation for Migration. (2006). Migrant's Remittances and Development: Myths, Rhetoric and Realities. Geneva. Retrieved from http://www.ssrc.org/workspace/images/crm/n ew_publication_3/\{d2915556-f851-de11-afac001cc477ec70\}.pdf

Jetley, S. (1987). Impact of Male Migration on Rural Females. Economic and Political Weekly, 22(44), WS47-WS53.

Jones, R. (1995). Ambivalent Journey: US Migration and Economic Mobility in North Central Mexico. Arizona: University of Arizona Press.

Kandel, W., \& Kao, G. (2001). Impact of Temporary Mexican Children's Educational Aspirations Performance. International Migration Review, 35(4), 1205-1231. Retrieved from http://www.jstor.org/stable/3092008

Khan, F. M. (1991). Migrant Workers to the Arab World: The Experience of Pakistan. In G. Gunatilleke (Ed.), Migration to the Arab World: The Experience of Returning Migrants. Tokyo: United Nations University.

McKenzie, D. J. A. (2007). Profile of the World's Young Developing Country Migrants. Background Paper to the 2007 World Development Report, WPS4021, October 2006, (pp. 3-7).

NSSO. (2010). Migration in India, 2007-2008. NSS 64th Round (July 2007-June 2008). NSS 
Report No.533 (64/10.2/2) (Vol. 533). New Delhi.

Nobles, Jenna. (2013) Migration and Father Absence: Shifting Family Structure in Mexico, Demography. Aug 2013; 50(4): 1303-1314.

Pattanaik, B.K. (2009). Young Migrant Construction Workers in the Unorganised Urban Sector. South Asia Research, 29(1), 1940.

Pitayanon, S. (1986). The Families of the Migrants. In M. Abella \& Y. Atal (Eds), Middle East Interlude: Asian Workers Abroad (p. 302). Bangkok: United Nations Educational, Scientific, and Cultural Organisation.

Planning Commission, Govt. of India. (2003). Criteria for Identification of Backward Districts, http://planningcommission.nic.in/reports/publi cations/tsk_idw.pdf, 7th Nov 2014.

PROBE Team. (1999). Public Report on Basic Education in India. New Delhi: Oxford University Press.

Ravenstein, E.G. (1885). The Laws of Migration, Journal of the Statistical Society of London, 48(2), 167-235

Roy, A.K. (2011). Distress Migration and Left Behind Women. Jaipur: Rawat Publishers.

Sajjad, H. (1998). Employment of Landless Labourers. New Delhi: B.R. Publishing.

Scalabrini Migration Center, O. W. W. A. (2004). Hearts Apart: Migration in the Eyes of Filipino Children (p. 70). Manila: Episcopal Commission for the Pastoral Care of Migrants and Itinerant People-CBCP / Apostleship of the Sea-Manila, 2004.

Singh, S.N., \& Yadava, K.N.S. (1981). On Some Characteristics of Rural Out-migration in Eastern Uttar Pradesh. Society and Culture, 12(1), 33-44.

Smita. (2008). Distress Seasonal Migration and its Impact on Children's Education. Creative Patheways to Access, Research Monograph No. 28. NUEPA. Retrieved from http://sro.sussex.ac.uk/1869/
Srivastava, R. (2012). Internal Migration in India Initiative: An Overview of its Features, Trends and Policy Challenges. National Workshop on Internal Migration and Human Development in India, 6-7 December 2011, Workshop Compendium, Vol 2: Workshop Papers (Vol. 2, pp. 1-47). Retrieved from Website: www.unesco.org/newdelhi

Taylor, E. (1987). Undocumented Mexico-U.S. Migration and the Returns to Households in Rural Mexico. American Journal of Agricultural Economics, 69, 626-637.

UNICEF. (n.d.). Children and Migration for Every Child Health, Education, Protection. Advance Humanity. Retrieved from http://www.globalmigrationgroup.org/uploads /gmg-

topics/children/3.B_Policy_brief_children_migr ation_June07.pdf

United Nations Children's Fund. (2010). Children in China: An Atlas of Social Indicators (pp. 110-111). Beijing.

Van de Glind, H. (2010). Migration and Child Labour: Exploring Child Migrant Vulnerabilities and those of children left-behind. Working Paper for ILO's International Programme on the Elimination of Child Labour (IPEC). Geneva, ILO. Retrieved from www.ilo.org/ipecinfo/product/download.do?ty pe=document $\&$ id $=14313$.

Vladicescu, N., Cantarji, V., \& Jigau, I. (2008). The Impact of Migration and Remittances on Communities, Families and Children in Moldova. UNICEF Division of Policy and Practice, New York. Retrieved from http://scholar.google.com/scholar?hl=en\&btnG $=$ Search \&q=intitle:The+impact + of + migration $+a$ nd+remittances+on+communities, +families+an $d+$ children+in+moldova\#1

Whitehead, A., \& Hashim, I. (2005). Children and Migration. Background paper for DFID Migration Team. London, Department for International Development. Retrieved from http://www.childtrafficking.com/Docs/dfid_05 _child_mig_bac_0408.pdf 
World Bank. (2007). Migration Closes Gender Gap, Brings Other Social, Health Gains. Retrieved from

http://www.ssrc.org/workspace/images/crm/n ew_publication_3/\{d2915556-f851-de11-afac001cc477ec70\}.pdf

\section{Acknowledgements}

This paper was presented in the 'International Seminar on Internal Migration and
Urbanisation and their Socioeconomic Impacts in Developing Countries: Challenges and Policy Responses' held in Fuzhou, China, 10-12 December 2011. The authors acknowledge the participants who gave their valuable advice and suggestions for the overall improvement of the paper. 